\title{
A PERDA DE DIREITO À CIDADE E A RAZÃO CÍNICA: A NATURALIZAÇÃO DA REPRESENTAÇÃO DE IMAGEM DA CIDADE
}

\section{THE LOSS OF THE RIGHT TO THE CITY AND CYNICAL REASON: THE NATURALIZATION OF THE IMAGE REPRESENTATION OF THE CITY}

\section{Rogério Rodrigues ${ }^{1}$}

\section{RESUMO}

O objetivo deste ensaio é analisar a perda de direito à cidade na impossível interpretação crítica do sujeito referente ao modo de representação de imagem que se pauta na razão cínica. Partimos da hipótese de que vivemos a ampliação da razão cínica, em que a representação midiática das imagens da cidade se produz como verdade. Estes modos de representação de imagens se impõem no campo da razão cínica como forma de racionalidade que naturaliza as interdições que se encontram nas cidades. A metodologia utilizada encontra-se no campo da teoria crítica, no sentido da apropriação do conceito filosófico de representação de imagem. Busca-se colocar em evidência que a razão cínica promove a destituição do pensamento crítico referente ao não lugar ou à perda de pertencimento do sujeito na cidade e que, em última instância, se apresenta com a precarização da cidadania. Concluímos que a cidade, pelo viés do olhar crítico, se conduz por práticas democráticas de narrativas da representação de imagem referentes à realidade no conjunto das contradições e isso seria, em parte, a possibilidade de os sujeitos recuperarem a razão crítica no sentido pensar o direito à cidade numa atividade de coerência para a vida democrática dos sujeitos.

Palavras-chave: Direito. Imagens. Representação. Cidade. Democracia.

\section{ABSTRACT}

The aim of the essay is to analyze the loss of the right to the city in the subject's impossible critical interpretation regarding the way of image representation that is based on cynical reason. We start from the hypothesis that we live the expansion of cynical reason, in which the media representation of the images of the city is produced as truth. These modes of image representation are imposed in the field of cynical reason as a form of rationality that naturalizes as interdictions that are mentioned in cities. The methodology is used in the field of critical theory, in the sense of appropriating the philosophical concept of image representation. It seeks to put in evidence that the cynical reason

\footnotetext{
${ }^{1}$ Graduação em Educação Física - UNESP 1987, Especialista em Educação Física - UNICAMP - 1988, Mestre em Educação - UNICAMP - 1997, Doutor em Educação - UNICAMP - 2004, Pós Doutor Filosofia da Educação - USP 2017. Afiliação:Universidade Federal de Itajubá - UNIFEI Lattes: http://orcid.org/0000-0003-2657-7302 ORCID: http://orcid.org/0000-0003-2657-7302. E-mail: rrunifei@hotmail.com
} 
promotes the dismissal of critical thinking regarding the non-place or the loss of the subject's belonging in the city and that, ultimately, it presents itself with the precariousness of citizenship. We conclude that the city, from the point of view of the critical eye, is guided by democratic practices of narratives of image representation referring to reality in the set of contradictions and this would be, in part, the possibility for the subjects to recover the critical reason in the sense of thinking the right to the city in an activity of coherence for the democratic life of the subjects.

Keywords:Law. Images. Representation. City. Democracy.

\section{INTRODUÇÃO - A PERDA DE DIREITO À CIDADE E A IMAGEM DA CIDADE COMO FORMA DE REPRESENTAÇÃO QUE NATURALIZA A REALIDADE E DESTITUI SUAS CONTRADIÇÕES}

Para se pensar a perda de direito à cidade e a questão da imagem como forma de representação da realidade, torna-se importante colocar em evidência o conjunto de contradições que ocorrem na aplicação dessa questão, pois, em grande parte, as atividades no campo das relações humanas se apresentam no entorno dos interesses específicos de dominação e de apropriação do saber. Neste sentido, o sujeito, para se inserir e adequar-se ao sistema produtivo, acaba por se pautar no paradoxo da representação de imagem, que busca anular os modos efetivos da exclusão do outro para uma forma interessada de colaboração, mais especificamente, a falsa coletividade interessada nas finalidades particulares daqueles que monopolizam os meios de produção.

O sistema capitalista em seu pleno funcionamento é um modo de fazer as coisas que opera no paradoxo de excluir o outro e, ao mesmo tempo, de precisar do outro. Essa ambivalência ocorre uma vez que a produção é coletiva, mas a apropriação da riqueza produzida é individual. Para o seu pleno funcionamento, os sujeitos encontram-se na condição de alienação ao não quererem saber sobre isso e continuarem fazendo o mecanismo da exploração, ou ao se manterem na consciência cínica, que sabe da exploração, mas também continua fazendo o referido processo no elogio do outro incluído e na exclusão deste das formas de vida em sociedade.

Essa base de exploração do outro, que opera de um lado incluindo, e de outro excluindo, é algo inerente ao modo de funcionamento da produção capitalista. Isso torna o sistema um lugar em que o sujeito adoece por completo no campo das relações humanas, uma vez que esse paradoxo não se resolve. Sobre isso, Freud (1996) já tinha anunciado que:

O elemento de verdade por trás disso tudo, elemento que as pessoas estão tão dispostas a repudiar, é que os homens não são criaturas gentis que desejam ser amadas e que, no máximo, podem defender-se quando atacadas; pelo contrário, são criaturas entre cujos dotes instintivos deve-se levar em conta uma poderosa 
quota de agressividade. Em resultado disso, o seu próximo é, para eles, não apenas um ajudante potencial ou objeto sexual, mas também alguém que os tenta satisfazer sobre ele a sua agressividade, a explorar sua capacidade de trabalho sem compensação, utilizá-lo sexualmente sem o seu consentimento, apoderar-se de suas posses, humilhá-lo, causar-lhe sofrimento, torturá-lo e matá-lo - Homo homini lupus. (FREUD, 1996, p. 116).

No campo das relações humanas, essa verdade sobre o sujeito se contradiz no modo racional em não querer saber da agressividade e isso pode transparecer em outras formas de fazer o que o sujeito sabe, mas faz o que se pauta no cinismo, como forma de mentira ou da falta de verdade em que se vive com o outro. Essa compreensão da razão cínica permite ao sujeito conviver com a falta de verdade para que possa transparecer superficialmente algo que permita o modo de funcionamento do capitalismo, inclusive a vida coletiva no interior das cidades.

Neste contexto, a perda de direito à cidade e as formas de representação de imagem da mesma buscam reafirmar essa falsa harmonia do convívio público e impedem de colocar em evidência, a repulsa e agressividade que se apresentam perante o outro. Portanto, nosso interesse se volta em analisar essa discordância entre o que o sujeito é e aquilo que se diz da representação de imagem da cidade. Para tanto, o eixo central deste ensaio é analisar as representações de imagens da cidade que se constituem no campo da razão cínica como algo que se desloca da alienação, em que se "Eles não sabem, mas o fazem" (SAFATLE, 2008, p. 67), para a condição paradoxal de que "[...] eles sabem o que fazem, e continuam a fazê-lo" (SAFATLE, 2008, p. 69).

A partir de determinado trabalho educativo tem-se a ilusão de que o homem possa saber e, principalmente, realizar o modo correto de fazer as coisas no campo da racionalidade, de modo a resultar na contenção da agressividade para que este se torne corretamente produtivo e consumidor. No entanto, a saída freudiana é mais conveniente, afirmando a impossibilidade de o sujeito redirecionar toda sua agressividade, mas resta saber:

Quais os meios que a civilização utiliza para inibir a agressividade que se the opõe, torná-la inócua ou, talvez, livrar-se dela? [...] O que acontece neste para tornar inofensivo seu desejo de agressão? Algo notável, que jamais teríamos adivinhado e que, não obstante, é bastante óbvio. Sua agressividade é introjetada, internalizada; ela é, na realidade, enviada de volta para o lugar de onde proveio, isto é, dirigida no sentido de seu próprio ego. Aí, é assumida por uma parte do ego, que coloca contra o resto do ego, como superego, e que então, sob a forma de 'consciência', está pronta para pôr em ação contra o ego a mesma agressividade rude que o ego teria gostado de satisfazer sobre outros indivíduos, a ele estranhos. A tensão entre o severo superego e o ego, que a ele se acha sujeito, é por nós chamada de sentimento de culpa; expressa-se como uma necessidade de punição. A civilização, portanto, consegue dominar o perigoso desejo de agressão do indivíduo, enfraquecendo-o, desarmando-o e estabelecendo no seu interior um agente para cuidar dele, como uma guarnição numa cidade conquistada. (FREUD, 1996, p. 127). 
Essa forma de racionalidade que oscila entre "não querer saber e faz" e "o saber que faz" condiz com a impossibilidade da realização do sujeito no processo de emancipação no campo da consciência crítica. Isso seria a nossa grande preocupação no sentido de compreender como os processos formativos destituem o campo da consciência cínica na formação de um tipo de sujeito que perca por completo sua sensibilidade e compaixão para com o outro e o torna objeto, como uma peça de máquina na vida coletiva. Esse sujeito sabe que imprime a dor ao outro e continua a fazer por exigir que todos sejam tratados como coisa e isso se apresenta na condição de realizar o pressuposto de: "Quem é severo consigo mesmo adquire o direito de ser severo também com os outros, vingando-se da dor cujas manifestações precisou ocultar e reprimir" (ADORNO, 1995, p. 128).

Entretanto, grande parte desta intencionalidade do cinismo em saber e fazer não se apresenta em evidência nos discursos entre os sujeitos, pois, em última instância, o que se anuncia é amar o próximo e como é importante viver em coletividade. Para que esta distorção perante a representação da realidade ocorra, tem-se que operar um mecanismo de insinceridade, pois:

Chamamos de insinceridade distorções da linguagem em sua relação com a intencionalidade. Pois aqui a linguagem aparece como máscara para a expressão da intencionalidade do falante, como, por exemplo, nos casos de hipocrisia e máfé. Chamamos ainda de mal-entendido situações nas quais a distorção entre intencionalidade e expressão é fruto da inabilidade do falante ou do ouvinte (SAFATLE, 2008, p.25).

Primordialmente, a vida coletiva apresenta as injunções decorrentes entre o que se pensa e o que se faz, ou a falta de junção entre o amor e o ódio perante o outro. Isso significa que, nos espaços urbanos, esses agrupamentos de sujeitos têm que viver juntos, mas, ao mesmo tempo, repudiam uns aos outros e se relacionam apenas contratualmente como coisas. Portanto, produzem um tipo de vida instrumental na cidade, em que se perde a condição da experiência humana. É possível dizer que esse é o grande sintoma da modernidade: precisa-se viver junto, mas simultaneamente não se quer estar junto com outro. Para se dar conta dessa ambiguidade do sujeito, as formas de representação se curvam para narrativas em torno da racionalidade do sujeito dócil e amplamente habilitado para atender as exigências do modo de produção que se pauta em formas de controle (FOUCAULT, 1991).

As formas de representação das cidades se tornam cada vez mais ampliadas em sistema de vigilância e controle, portanto, em nossa contemporaneidade, torna-se comum a representação da vida nas cidades em torno das câmeras de segurança e dos smartphones de uso pessoal, em que cada sujeito vigia o outro que ocupa o espaço urbano. Logo, quem anda pelas ruas parte do pressuposto de que o outro está sendo vigiado e controlado. 
Partimos da hipótese de que, se vivemos nas contemporaneidades das cidades, a representação midiática dos sistemas eletrônicos se impõe no campo da razão cínica como forma de racionalidade que produz determinada verdade. Compreendemos que, no campo da razão cínica, esses modos de verdade ocorrem nas mediações entre o sujeito e a realidade que elimina ou destitui os elementos contraditórios. Neste caso, compreendemos que a representação dos espaços urbanos se encontra, em grande parte, determinada, primordialmente, pelo viés dos dispositivos das mídias eletrônicas que estabelecem a hegemonia da banalização dos elementos da realidade comuns a todos.

Nesta interface entre o sujeito, o campo das mídias eletrônicas e o espaço urbano é que podemos analisar a representação da realidade referente ao espaço urbano como perda da experiência do olhar, pois basta caminhar pela cidade e observar a riqueza de detalhes que passa despercebida aos olhos em nosso cotidiano. Essa compreensão pode indicar a impossibilidade de instaurar a crítica ao se constatar, basicamente, a perda de representação dos espaços urbanos nas interdições presentes na cidade. Existe, também, uma falta de querer saber que temos: um lugar para andar, em oposição ao lugar para não andar; rua fechada, em oposição à rua aberta e, por último, o olhar que não vê, em oposição ao ver que não pode olhar. Portanto, este estudo se justifica como uma análise crítica em torno da razão cínica que reproduz a verdade na anulação das contradições da polaridade da representação da realidade entre a cidade aberta e a cidade fechada (SENNETT, 2018) que se trata de compreender que,

[...] para conhecer a cidade, é preciso estabelecer outras formas de relações com o lugar onde se constrói e se habita, em que se possam perceber as sutilezas que contornam os espaços, principalmente enfrentar a questão de como nos produzimos a nós mesmos como sujeitos, quando fazemos coisas e, no caso específico do texto em análise, fazendo da cidade um lugar de se construir e morar, que se estabelece na dualidade de relações abertas ou fechadas (RODRIGUES, 2020, p. 60).

A falta de entendimento sobre essas representações de cidade (aberta ou fechada) se apresenta como resultado da naturalização desses elementos na vida dos sujeitos que perdem a condição reflexiva sobre o direito à cidade. Portanto, no campo da teoria crítica, devemos ficar atentos para desconstruir a naturalização da representação, referente às barreiras físicas presentes na realidade, que se apresenta como forma de senso comum ao determinar os contornos da cidade.

Em relação ao estudo das cidades, partimos do pressuposto de que vivemos na contemporaneidade, na hegemonia das mídias eletrônicas, a perda da experiência do pensamento, em que o olhar e ver estão separados pelas formas de representação da realidade. Isso, que retorna como representação, muitas vezes busca dizer algo, mas o que se diz não se encaixa muito naquilo 
que é visto, pois "[...] não adianta dizer o que se vê; o que se vê não habita jamais o que se diz [...]" (DELEUZE \& GUATTARI, 2014, p. 107).

Devemos partir do critério segundo o qual as narrativas que se produzem a partir daquilo que se vê não devem se apresentar como verdade e anulam por completo o trabalho do pensamento crítico, pois nos encontramos em um mundo em que as imagens também se encontram subordinas ao trabalho da razão cínica. Esta modalidade de razão cínica se apresenta como forma de pensamento de maneira que:

[...] é impotente diante de um regime de distorções cada vez mais hegemônico, que poderíamos chamar de distorções performativas. Neste caso, a linguagem produz performances que não deveria produzir, como no caso dos sintomas (que indicam a existência de duas regras de conduta linguisticamente estruturada contrárias que constituem uma mesma representação mental), ou não produz performances que deveria produzir, mesmo estando perfeitamente adequada em relação aos critérios normativos partilhados de maneira intersubjetiva. Essa distorção performativa paradoxal ou esse bloqueio de força perlocucionária de ser chamado de cinismo (SAFATLE, 2008, p.26).

Essas produções, no campo das "distorções performativas" (SAFATLE, 2008), se constituem a partir de narrativas que têm como resultado a redução da crítica ao interpretar o mundo e a si mesmo, como a síntese de poucas determinações que excluem a impossibilidade de pensar o conjunto das contradições em que as coisas se naturalizam no modo como vivemos nas cidades. Esse modo natural de interpretar o mundo a partir da imagem produzida pela mídia eletrônica se apresenta reduzido pela própria questão técnica do aparelho, em que o foco da câmera ou enquadramento da imagem se apresenta como um recorte da realidade. Esse tipo de recorte da realidade é despercebido pelo modo que o olhar assume a imagem como representação da realidade, que, associado às narrativas que se juntam à mesma, pode produzir outros sentidos, que, muitas vezes, se constituem em completa perda de sentido quando inserida em determinado contexto. O recorte da imagem, em se tratando de representação da cidade, pode constituir outros sentidos e, em muitos casos, elimina o conjunto das contradições que se encontram presentes na realidade.

Essas produções se tornaram popularmente conhecidas como Fake News (notícia falsa) e, no caso deste ensaio, podemos denominar por similitude as representações de cidade que se tornam produções de imagens no entorno de narrativas como Fake City (cidade falsa). Compreendemos que essas imagens produzem narrativas da realidade com a sofisticada finalidade de produzir alguma forma de ganho no campo da razão cínica ao divulgar a informação que distorce por completo os fatos que compõem a representação da cidade.

Neste caso, o que está em jogo é a produção de outros verdadeiros sentidos que se impregnam como formas absolutas de compreensão na exatidão do pensamento e, 
simultaneamente, inibem o sujeito para o não pensar a diferença "[...] no sentido de uma manifestação de deficiência, da cegueira e da impotência, quando ficam apenas estagnadas, no sentido da maldade, da teimosia e do fanatismo [...]" (ADORNO \& HORKHEIMER, 1985, p. 240). Portanto, o paradoxo dessa compreensão reduzida faz com que se amplie a imposição midiática da imagem, que determina o modo de pensar deste mundo que se encontra no paradoxo das ações performativas.

Esta irônica contradição se dá pela ampliação e pela distorção de sentido e, simultaneamente, pela destituição de sentido, que seria a hegemonia da teimosia em pensar as coisas como uma verdade absoluta e eterna. Isso se apresenta como forma política de governança que, em última instância, se torna ferramenta para a naturalização e, principalmente, para a manutenção das desigualdades sociais. No caso específico das cidades, a plena manutenção de formas de vida em cidades mantém as segregações dos sujeitos na ocupação do espaço urbano.

Em última instância, podemos compreender que essa modalidade de racionalidade da razão cínica se apresenta como forma de representação da imagem que naturaliza a realidade e destitui suas contradições. Isso implica em uma forma de sociedade na qual, cada vez menos, os sujeitos constituem formas de pensamentos críticos de acordo com o lugar onde vivem, no interior das cidades.

\section{ALGUNS APONTAMENTOS CRÍTICOS SOBRE A REPRESENTAÇÃO DE IMAGEM DA CIDADE E A FORMA DE PENSAR O DIREITO À CIDADE}

Partimos do pressuposto metodológico de que para se compreender o direito à cidade é preciso, em parte, discutir a forma de representação de imagem da realidade. Para tanto, partimos do desdobramento do mito da caverna de Platão como forma de analisarmos a representação de imagem como forma de conhecer a realidade em que se apresenta a alegoria contada em seu texto sobre a República, que narra a passagem de um pensamento que vive na escuridão e os sujeitos ali presos somente podem apreciar as imagens projetadas nas paredes no interior da caverna. Portanto, as coisas são conhecidas estritamente pela sua aparência (as sombras) como forma de representação. $O$ conhecimento da essência das coisas somente é possível com a saída da caverna, que permite ao sujeito ver as coisas como elas são num olhar de retidão, uma vez que ocorre a possibilidade de sair da caverna e contemplar a luz. Isso o permite ver como as coisas são na essência e distingui-las da representação das sombras que se encontram nas paredes da caverna (PLATÃO, 1996, p. 317- 23)A partir deste conhecimento, quando o sujeito voltapara a escuridão, no interior da caverna, passa a falar a verdade das coisas para os outros que ali ficaram presos e produz as discordâncias entre todos. Assim, uma vez retornado à caverna e habituado novamente com a escuridão,

[...] sereis mil vezes melhores do que os que lá estão e reconhecereis cada imagem, o que ela é e o que representa, devido a terdes contemplado a verdade relativa ao belo, ao justo e ao bom (PLATÃO, 1996, p. 326). 
Neste contexto, a pergunta central neste ensaio é: como as formas de representação de imagem se constituem em um modo de pensar a realidade? Compreendemos que as representações de imagens podem se constituir como elemento crítico de vida dos sujeitos na cidade na desconstrução da banalização das sombras do elemento comum, pautada por narrativas da razão cínica da modernidade. Entretanto, a modernidade, pelo viés das mídias eletrônicas no entorno das representações de imagens, se amplia à razão cínica, que tem como pressuposto a forma de verdade que esconde as contradições a fim de constituir outra narrativa em que

[...] o cinismo só pode ser alçado à condição de lógica de racionalização social quando a linguagem passou por um processo peculiar de desagregação. Como sempre, é no campo da estética que primeiramente sentimos as desagregações da linguagem (SAFATLE, 2008, p.26).

Em última instância, o ensaio também questiona: como se torna possível, no campo das narrativas, o sujeito conhecer a coisa em si referente aos espaços urbanos?

Torna-se importante analisarmos, em detalhe, como a modernidade inaugura o pressuposto epistemológico da forma de representação do sujeito perante a realidade. Neste contexto é que a formação do pensamento crítico é algo que estabelece a distinção entre as narrativas do senso comum e a análise do trabalho do pensamento, no sentido de "desbanalizar" o que é comum a todos em que

[...] não se propõe a enxergar a mais que outros. Ela não acredita que pode alimentar vanguardas. Ela está longe de achar que a tarefa da filosofia é "tirar o véu" do real, descobrindo sua verdade, ou acreditar que pode "fabricar" o real, produzindo sua verdade. A filosofia como desbanalização do banal não procura a "realidade por detrás da ilusão". Não há nada que se possa dizer que está atrás ou na frente. Abordamos o cotidiano como aquilo que nós vivemos corriqueiramente. Trata-se do que é mais visto e, de fato, mais conhecido entre nós. Não estamos numa Caverna. Estamos muito bem à luz do sol. Olhamos tudo e conhecemos quase tudo. Fazer filosofia, portanto, na minha acepção, não tem a ver com a atividade de uma vanguarda que enxergaria o que está abaixo ou por detrás do real, que outros não estariam vendo. No trabalho que faço, o que importa é contar uma boa história, é produzir uma boa narrativa, é contar alguma coisa sobre as nossas práticas diárias que possa ser posta na mesa, no leque das outras perspectivas que estão sendo necessariamente geradas por outros (GHIRALDELLI, 2021).

Compreendemos o processo de desbanalizar o que é comum à modernidade como lugar em que ocorre a ruptura com um mundo explicado pelas formas das crenças religiosas para a razão soberana em que se inaugura o sujeito conhecimento. Esse marco se encontra a partir de René Descartes que estabelece o método da razão como forma soberana para se conhecer a realidade. Entretanto, sobre esse caminho, ele declara que: “[...] o meu desígnio não é ensinar aqui o método 
que cada qual deve seguir para bem conduzir sua razão, mas apenas mostrar de que maneira me esforcei por conduzir a minha (DESCARTES, 1987, p.30).

Podemos observar que, ao estabelecer o caminho do seu método de investigação da realidade, Descartes teve que realizar um mergulho no seu tempo, pois considerava que "[...] é bom saber algo dos costumes de diversos povos" (DESCARTES, 1987, p.31), como forma de apropriar-se da realidade.

Essa vertente cartesiana se constitui na res cogito como lugar do pensamento para se compreender a res extensa lugar em que se encontra a coisa em si. Para validar essa mediação entre a representação do pensamento e a coisa em si, utiliza-se o artifício da existência de deus como forma de garantir que não esteja enganado sobre aquilo que se pensa, pois

Em seguida, refletindo sobre o fato de que eu duvidava e de que, por conseguinte, meu ser não era completamente perfeito, pois via claramente que conhecer era maior perfeição que duvidar, ocorreu-me procurar de onde aprendera a pensar em alguma coisa mais perfeita que eu; e soube, com evidência, que devia ser de alguma natureza que fosse, efetivamente, mais perfeita. [...] De modo que ela só podia ter sido inculcada em mim por uma natureza que fosse mais perfeita do que eu, e até que tivesse em si todas as perfeições de que eu poderia ter alguma idéia, isto é, para explicar-me numa só palavra, que fosse Deus (DESCARTES, 1996, p. 39-40).

Para Descartes, a constituição do sujeito do pensamento se apresenta, na dúvida metódica, como elemento decorrente, mas falta compreender como se pode evitar que todo o saber possa ser resultado de um pensamento enganoso. Assim sendo, todo o conhecimento do mundo se apresenta colocado em dúvida, pois todas as certezas devem ser abaladas, inclusive, a própria existência do sujeito cognoscente é colocada em questionamento. Ao colocar tudo em dúvida, acaba-se constatando uma primeira certeza: a da existência do eu. Ou seja, ao instaurar a dúvida, Descartes conclui que o sujeito esteve, a todo momento, pensando. Temos, assim, a máxima cartesiana: "eu penso, logo existo" (DESCARTES, 1987, p. 46). Para Descartes, essa premissa "[...] era tão firme e tão certa que todas as mais extravagantes suposições dos céticos não seriam capazes de a abalar, julguei que poderia aceitá-la, sem escrúpulo, como o primeiro princípio da Filosofia que procurava" (DESCARTES, 1987, p. 46).

A nossa preocupação moderna centrou-se apenas em querer certezas a partir das evidências sobre a possibilidade de formar um eu cognescente, que pudesse alcançar a razão verdadeira, ou seja, como as coisas realmente podem ser representadas para o sujeito. Neste termo, fica claro que o conhecimento da idéia de realidade inaugura na modernidade como forma de representação metafísica em que o que prevalece é a forma de narrativa das certezas estabelecidas que possam permitira constituição entorno do objeto do conhecimento. 
No campo desta inauguração da tradição moderna de representação da coisa em si estavaa possibilidade de conhecer o objeto e, portanto, a apropriação da realidade apresenta outras formas de conhecê-la no que diz respeito à verdade constituída a partir da narrativa que o sujeito produz.

A partir do sujeito do conhecimento cartesiano se inaugura o idealismo, que, em formas distintas a esse modo de representação, podemos identificar basicamente, outras duas possibilidades de conhecimento da coisa em si no campo da epistemologia: empirismo e dialética.

No caso do empirismo, partimos de David Hume (1721-1776), no seu tratado sobre "A investigação sobre o entendimento humano" (1748). Ele parte do pressuposto de que o sujeito se contrapõe ao idealismo cartesiano ao estabelecer que o conhecimento parte das coisas em si, uma vez que:

O homem é um ser racional e, com tal, recebe da ciência sua adequada nutrição e alimento. Mas os limites do entendimento humano são tão estreitos que pouca satisfação se pode esperar neste particular, tanto pela extensão como pela segurança de suas aquisições (HUME, 2006, p. 9).

Neste caso, estamos no campo da tradição iluminista, em que o esclarecimento permite o entendimento da realidade, na qual o uso da racionalidade humana permite conhecer plenamente o mundo. Para tanto, deve-se

[...] examinar seriamente a natureza do entendimento humano e mostrar, por meio de uma análise exata de suas faculdades e capacidades, que ela não é, de nenhuma maneira, adequada a assuntos tão remotos e abstrusos. O raciocínio exato e justo é o único remédio universal adequado a todas as pessoas e aptidões, o único capaz de destruir a filosofia abtrusa e o jargão metafísico que, mesclado com a superstição popular, se tornam, por assim dizer, impenetráveis aos pensadores descuidados e se afiguram como ciência e sabedoria" (HUME, 2006, p. 14-15).

Portanto, o "raciocínio exato e justo" se apresenta como construção tendo como fundamento os elementos da realidade. Entretanto, a dinâmica da realidade impõe os elementos da contradição que determina que o conhecimento da coisa em si não está no sujeito da razão, nem na sensação do objeto, e sim no campo das interações que se produzem na análise decorrente do trabalho do pensamento a partir dos próprios elementos contraditórios. Estamos nos referindo ao campo da dialética em que temos como referência o pensamento de Karl Marx, que anuncia que o modo de pensar a vida na sociedade se encontra no campo da disputa das formas ideológicas e são formas especificas de interpretar o mundo (MARX, 1983). Para este autor, torna-se importante analisar como a ideologia se apresenta no modo de produzir a interpretação da realidade e, em última instância, impede a realização plena da humanização, uma vez que vivemos alienados no modo de produção capitalista. Portanto, o modo como produzimos a nossa subsistência constitui também um modo especifico de pensar a realidade, quando se parte da hipótese que "O homem da 
sociedade comunista será o homem total, livre das alienações e mutilações impostas pela divisão do trabalho reinante na sociedade burguesa e apto a realizar suas múltiplas potencialidades" (GORENDER, 1998, p. XVI).

No caso deste ensaio, nossa hipótese de análise referente à forma de representação da cidade é a de que os elementos empíricos da realidade e sua compreensão no campo da dialética se encontram subordinados como elementos ideológicos da razão cínica, que naturaliza a realidade e destitui suas contradições. Portanto, no campo da representação da realidade, trocamos o artifício cartesiano de Deus para constituir a verdade pelas mídias eletrônicas, que conferem o grau de verdade a outras formas de verdade, referentes às narrativas que se produzem sobre a vida dos sujeitos perante o espaço político da vida nas cidades.

Nos dias atuais, o sujeito às narrativas sobre a dinâmica da realidade se apresenta em torno de diversas formas de exposição do pensamento nas quais o conhecimento se desloca do campo da epistemologia para o lugar dos seguidores de celebridades quantitativas. Isso ocorre mais especificamente na linguagem das redes sociais por aqueles que se denominam personalidades e possuem "curtidas" em suas fotos e dizeres. Isso seria uma forma de validação da narrativa produzida não por aquilo que se diz, mas por aquilo que se faz, diretamente pelas ações nas redes sociais que se impõem como valor social de verdade.

Esse cenário desloca a nossa discussão do conhecimento da realidade por um conjunto de desempenho, que ocorre associado diretamente ao sujeito da imagem que se apresenta como aquele que produz suas próprias narrativas referente à realidade. Desse modo, o conjunto de seguidores que se mantém na rede social das personalidades passa ser decisivo como critério de verdade associado à representação de verdade do sujeito que diz algo sobre a realidade. Torna-se verdadeiro o paradoxo de famosos e celebridades anônimos que produzem, em seus espaços cibernéticos, um conjunto de narrativas e representações de imagens sobre a vida na cidade que os sujeitos aderem como verdade absoluta. É possível dizer que, em grande parte, o que se diz como verdade é algo que o sujeito deseja como forma de verdade sobre o modo de existir, que, cada vez mais, precariza os processos formativos e amplia à racionalidade para o surgimento da barbárie.

\section{O DIREITO À CIDADE E A ANULAÇÃO DAS NATURALIZAÇÕES DA REPRESENTAÇÃO DAS IMAGENS}

Podemos dizer que o caminhar pela cidade seja um modo específico de conhecer o espaço urbano e uma possível maneira de recuperar as formas de representação, pois isso se caracteriza como experiência sensorial em que o sujeito estabelece uma determinada relação entre o corpo e a cidade ou entre o olhar e pensar. Partimos do pressuposto de a cidade é um lugar em que representa 
os anseios dos sujeitos em decorrência de determinada concepção de mundo e sociedade que têm e que, na atual modernidade, gira em torno do individualismo. Neste contexto, o espaço privado é consolidado como uma forma de pensar a vida em sociedade, de maneira que os espaços urbanos ficam na polaridade entre estarem apropriados e, portanto, cercados, ou estarem completamente abandonados, como sendo um não lugar. Nesta polaridade, podemos compreender que a interface do sujeito com o espaço urbano seja:

[...] uma história da cidade contada através da experiência corporal do povo: como mulheres e homens se moviam, o que viam e ouviam, os odores que atingiam suas narinas, onde comiam, seus hábitos de vestir, de banhar-se e de que forma faziam amor (SENNETT, 1997, p. 15).

A questão que se coloca neste ensaio é que essa experiência sensorial de caminhar pela cidade pode se constituir como forma de colocar uma lente de aumento com a qual pode-se constatar, basicamente, as interdições em dois elementos contraditórios: o lugar para andar em oposição ao lugar para não andar; a rua fechada em oposição à rua aberta e, por último, olhar, e não ver em oposição ao ver, e não olhar.

Isso se condiz com elementos que se tornam banalizados, mas, pela posição filosófica, tornase oportuno colocar em discussão a raiz desta dualidade que interdita a circulação dos corpos dos sujeitos no espaço urbano. Torna-se pertinente analisar, no campo da teoria crítica, o conceito filosófico do lugar do sujeito na cidade. Inclusive, torna-se possível a referida compreensão, uma vez que já se tornou comum a concepção da não territorialidade do sujeito em relação ao seu lugar na cidade, em oposição ao não lugar.

Para analisar esta questão da representação de imagem, nos propomos a analisar os lugares em que os sujeitos se tornam presentes na cidade em oposição a não estar presentes, como forma de ausência que se torna algo naturalizado e banalizado como elemento comum a todos. Para tanto, partimos do pressuposto de estudar a cidade enquanto manifestação da questão econômica e social como forma de organização da presença e da ausência dos sujeitos e, principalmente, como se produz a representação de imagem da mesma. Essa imagem pode se tornar elemento determinante nesta forma de ocupar os espaços da cidade em que se rompem os laços de representação uma vez que

O segredo dessa sociedade na qual os vínculos com os objetos são frágeis, mas que é capaz de alimentar-se dessa fragilidade mesma está naquilo que chamamos de "ironizacão absoluta dos modos de vida". [...] Na verdade, eles são cada vez mais chamados a sustentar identificações irônicas, ou seja, identificações nas quais, a todo momento, o sujeito afirma sua distancia em relação àquilo que ele está representando ou, ainda, em relação a suas próprias ações (SAFATLE, 2008, p.134). 
No campo dessas formas de "ironização" ou aquilo que se expressa pelo cinismo na representação de imagem, temos, por um lado, aqueles que possuem concentração de renda e produzem as narrativas da inclusão que, em nada incluem o outro e, por outro lado, aqueles, de baixa renda, que vivem verdadeiramente excluídos e compreendem como parte de algo que dificilmente poderá fazer parte da vida na cidade. Compreendemos que essa idéia de estar dentro e fora deve ser pensada como linhas de espaços que são constituídos por uma malha intercambiável em que passa algo de um lado para o outro. O sujeito pobre entra no espaço do sujeito rico para trabalhar e vender serviço. O sujeito rico entra no espaço do sujeito pobre para comprar o serviço ou para ser atendido em suas necessidades de serviços. Em última instância, são os grupos de sujeitos com acúmulo de capital que precisam do conjunto de sujeitos desprovidos de renda para que tenham seu conforto garantido. Dentro desse contexto, a cidade se revela como resultado dessas contradições no campo dos espaços público e privado.

Entretanto, o que prevalece em nossa contemporaneidade da vida nas cidades é uma ampliação das tecnologias eletrônicas. Essa condição de fascínio pela tecnologia apresenta-se, de modo geral, na sociedade, de modo que alguns equipamentos se tornam comuns na vida dos sujeitos, por exemplo, o número de smartphones em uso no Brasil chega a 168 milhões de aparelhos (CAPELAS, 2017).

Sobre o predomínio dessas tecnologias, torna-se comum a idéia de que copiar a lição nas aulas acaba constituindo-se em algo completamente obsoleto. Segundo um professor de matemática no curso de engenharia, no momento atual, os alunos estão tirando foto do quadro de anotações do professor com seus smartphones e, portanto, perde-se, por completo, o sentido do registro gráfico das anotações.

No conjunto dessas tecnologias que se apresentam difusas na cidade e que podem ser naturalizadas, as contradições a partir da razão cínica é que colocamos em evidência, como já anunciado anteriormente, a oposição entre três elementos que selecionamos para analisar a representação da cidade: a) Lugar para andar e lugar para não andar; b) Rua aberta e rua fechada e c) Olhar, e não ver e ver, e não olhar.

Ao analisar o lugar para andar e lugar para não andar, compreendemos como existe o lugar que permite conduzir os nossos corpos pelos espaços urbanos e outros lugares que se apresentam interditados e se naturalizam como lugar para não andar. 

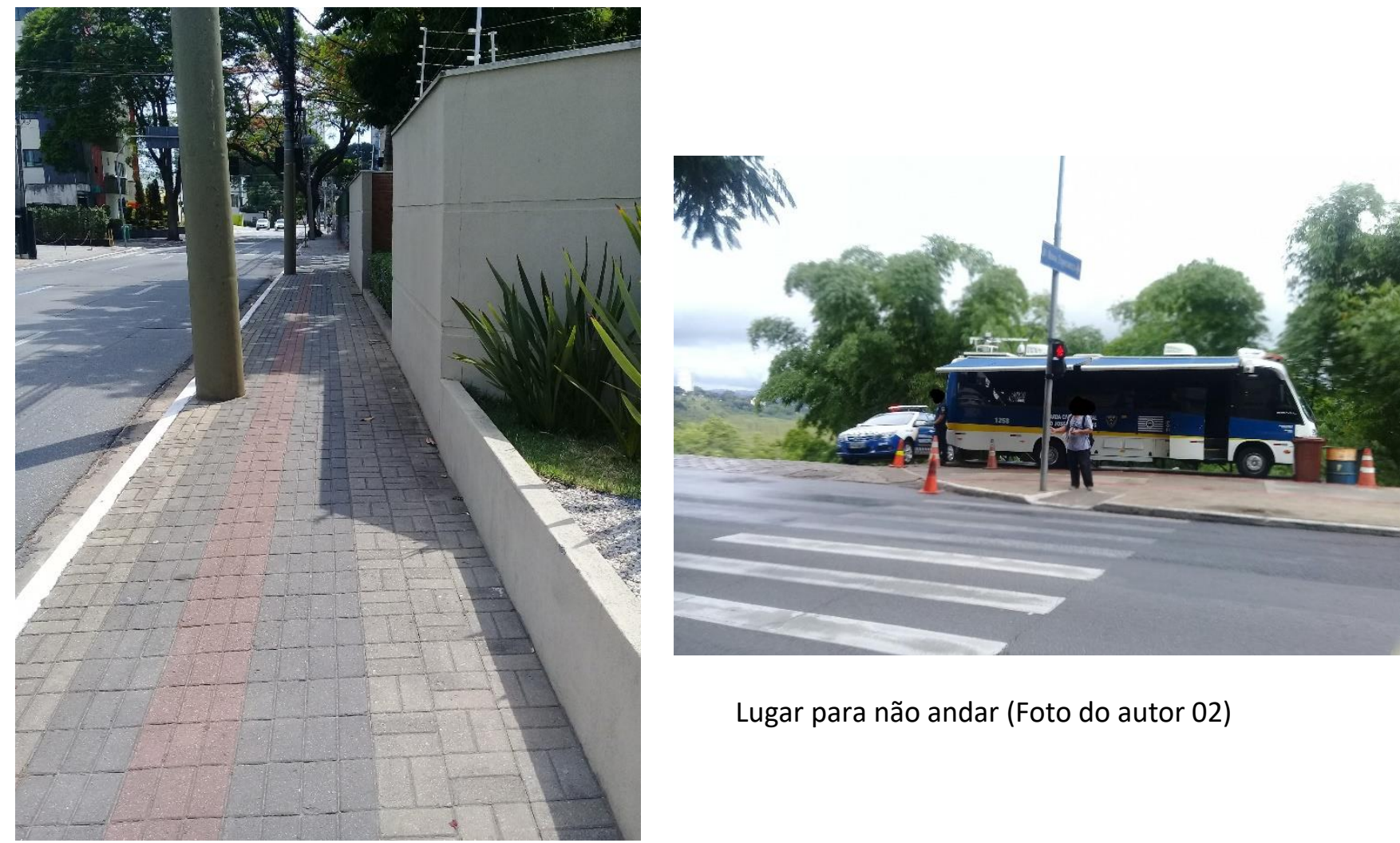

Lugar para não andar (Foto do autor 02)

Lugar para andar (Foto do autor 01)

O lugar para andar na cidade seria o delineamento feito pelas calçadas que traça e determina as linhas por onde o corpo do sujeito pode se deslocar no espaço urbano (Foto do autor 01).

O lugar para não andar são interdições que demarcam por onde o sujeito não deve se deslocar, pois são espaços estranhos ao local. Cabe destacar que, pelo senso comum, somente a comunidade local pode circular livremente no referido espaço, uma vez que isso serve de orientação pelo posto policial na entrada da comunidade (Foto do autor 02).

A afirmação decorre do fato de que, na entrada da comunidade, existe um posto policial permanente 24 horas por dia; ao perguntar para o policial de plantão, ele orientou que não se deve entrar no referido local por ser um lugar perigoso para pessoas estranhas. Isso condiz com um tipo de narrativa que se insere no conjunto de representação de imagens desses espaços em que o referido lugar encontra-se em completa ruptura com a cidade.

Essas formas de ruptura analisadas nos permitem avançar para outros desdobramentos, de forma que as interdições se polarizam entre a rua aberta e a rua fechada. Fica estabelecido pelo senso comum que existem espaços específicos para os sujeitos se deslocarem, alguns são apropriados como espaço privado e outros, públicos, encontram-se desprovidos de ocupação. 


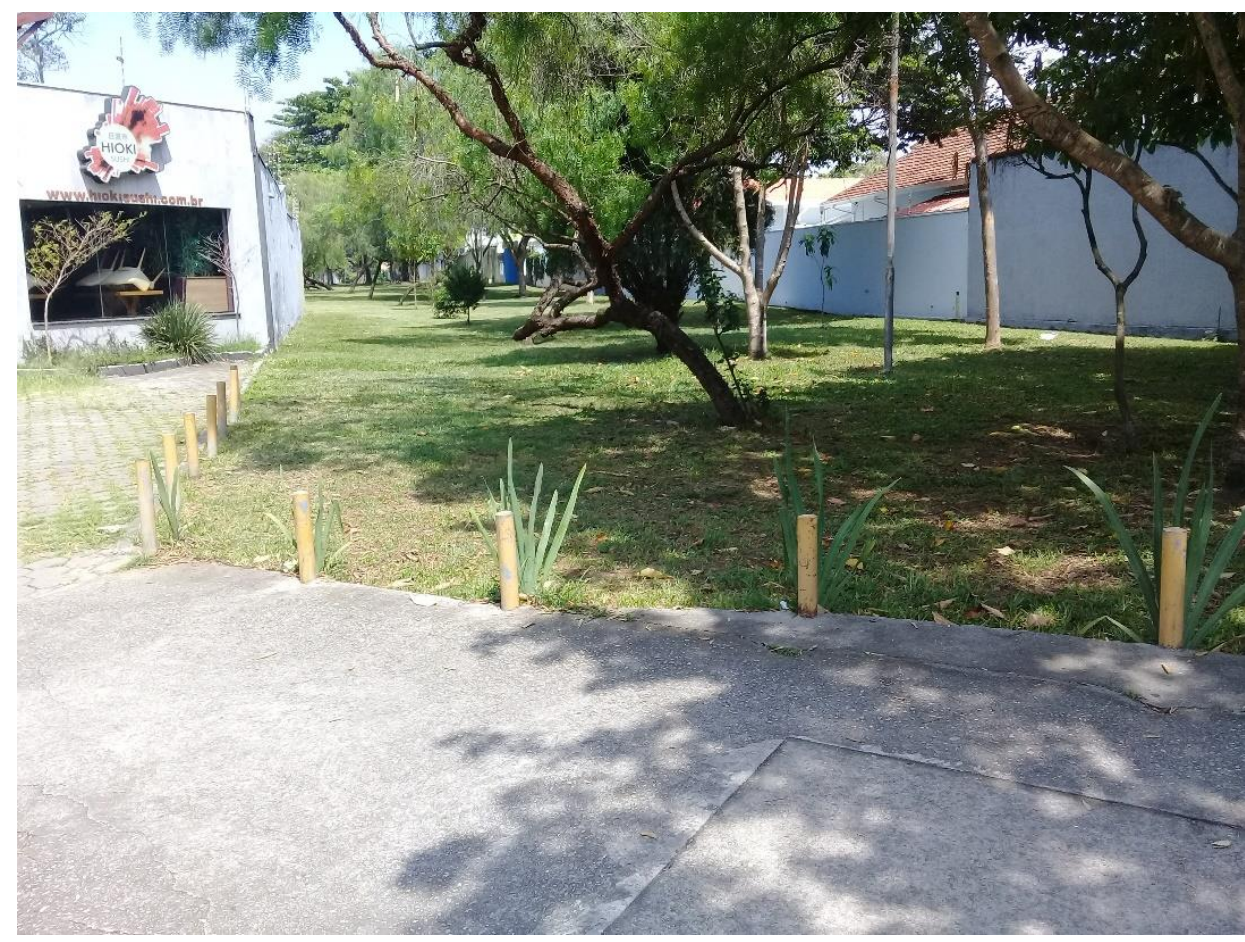

Rua aberta (Foto do autor 03)

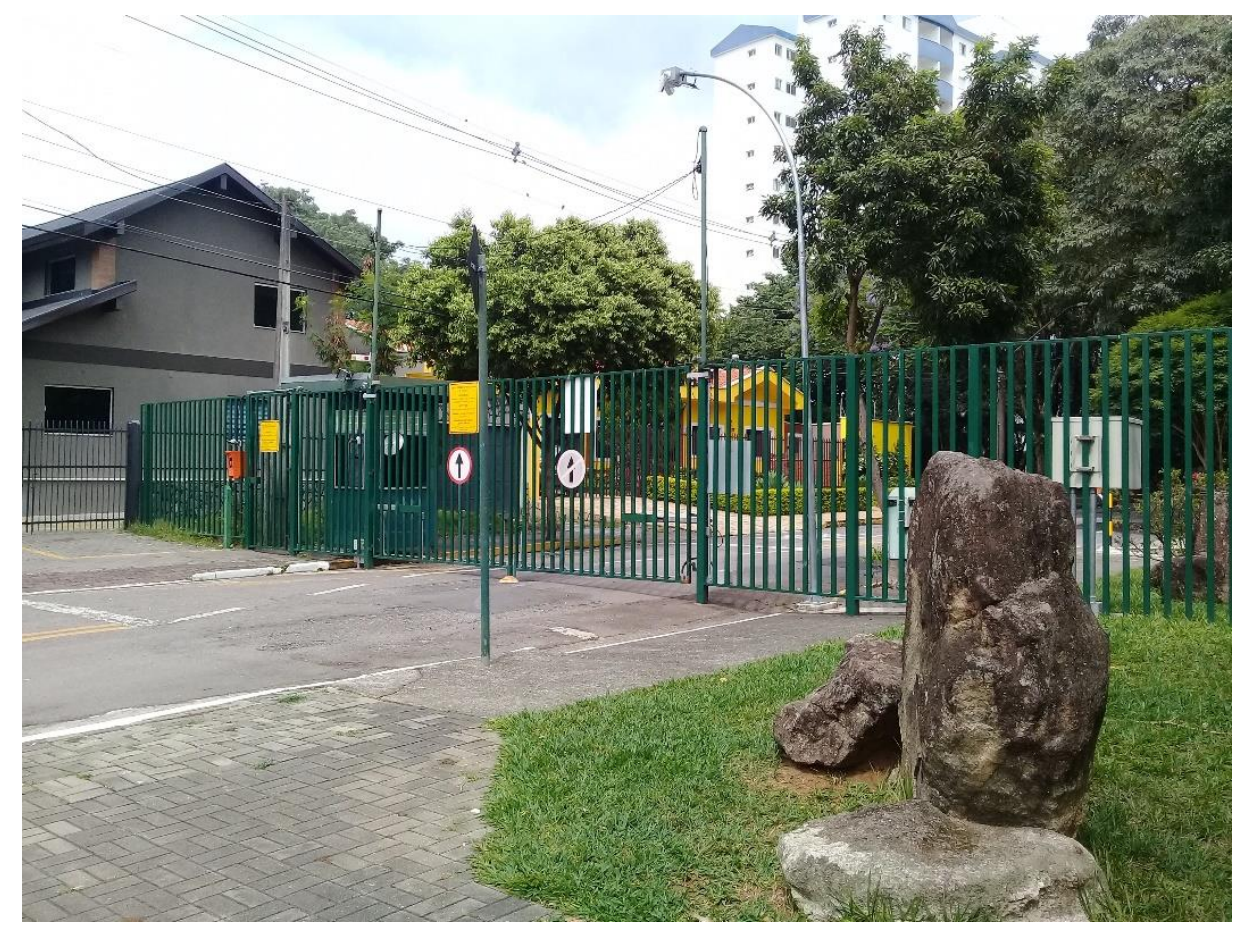

Rua fechada (Foto do autor 04)

O paradoxo da rua aberta consiste em que, quando ela é de todos, simultaneamente, não é de ninguém, pois se encontra completamente vazio o seu uso como lugar do sujeito interagir com a cidade (foto do autor 03). Esse modelo de espaço foi concebido como forma de se tornar uma área comum a todas as casas em que todos os sujeitos pudessem se encontrar num espaço comum. Em 
contrapartida ao lugar aberto e não ocupado, temos o lugar fechado, um condomínio particular no espaço público com o fechamento da rua (foto do autor 04). Nesse setor específico de fechamento da rua, encontramos portarias em cinco ruas púbicas que fazem do referido espaço um condomínio fechado em seqüência no centro da cidade. Isso acaba se constituindo num enorme quarteirão com o fechamento das respectivas ruas, conforme a foto abaixo. Para facilitar a identificação, fizemos um traçado em vermelho:

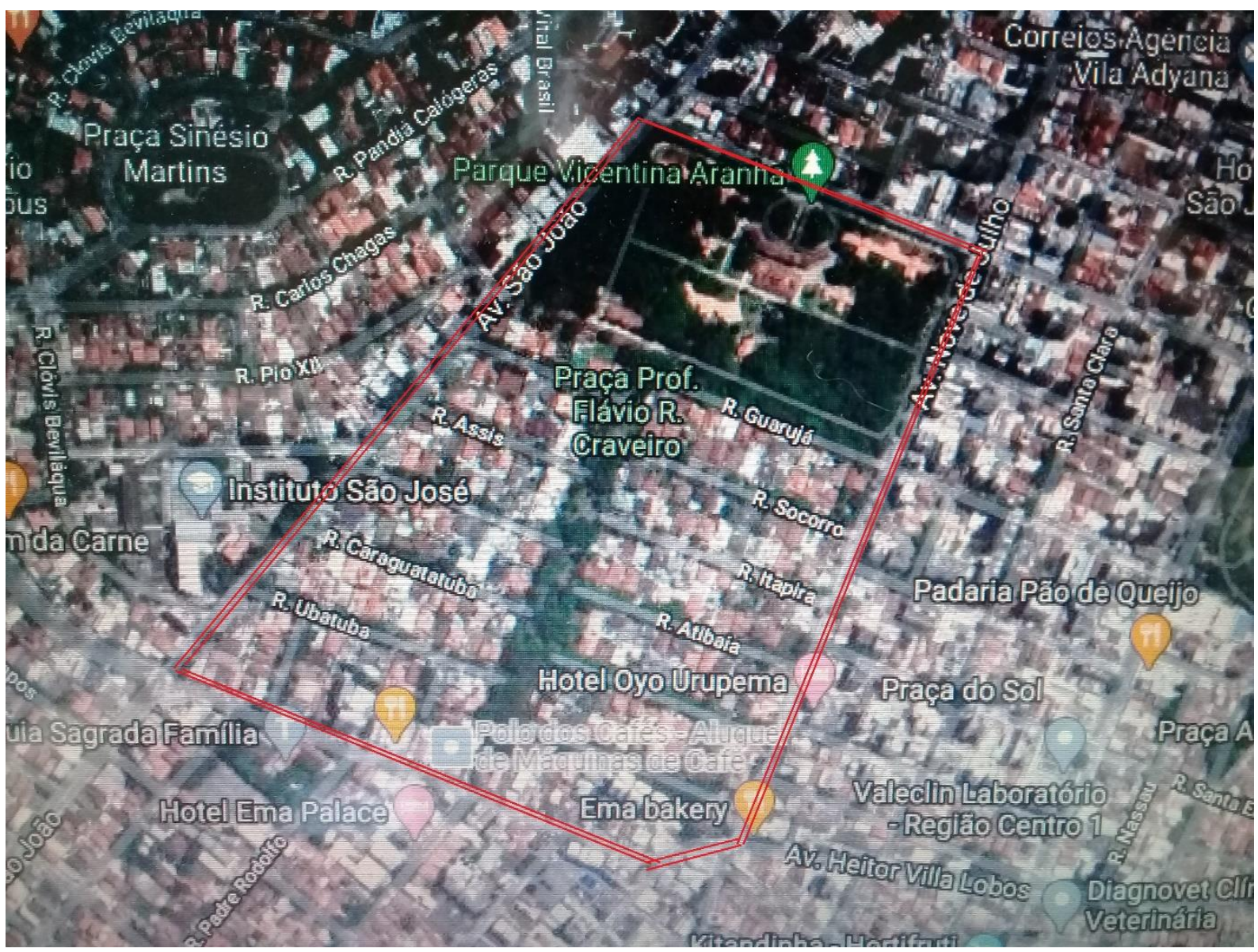

(Fonte - Google Maps)

Aqui também não se entra o estranho por não pertencer ao local, ou seja, por não ter propriedade no espaço fechado. Neste contexto, ambas as interdições se produzem: de um lado, por não pertencer à comunidade, de outro, por não ter a propriedade. Isso constitui a perda de direito à cidade, que se fecha por diversos modos para a circulação dos sujeitos.

Por último, compreendemos que a naturalização dessas contradições se expande também para as formas de tecnologias eletrônicas, na oposição entre olhar, e não ver e ver, e não olhar, porque perdemos a experiência do ver em detrimento do olhar e, portanto, ocorre a separação entre quando estamos vendo algo, mas não conseguimos olhar devido à própria naturalização da imagem à 
nossa frente, e quando olhamos, mas não se torna possível ver em decorrência da imagem que se encontra traduzida pelo viés das tecnologias eletrônicas.

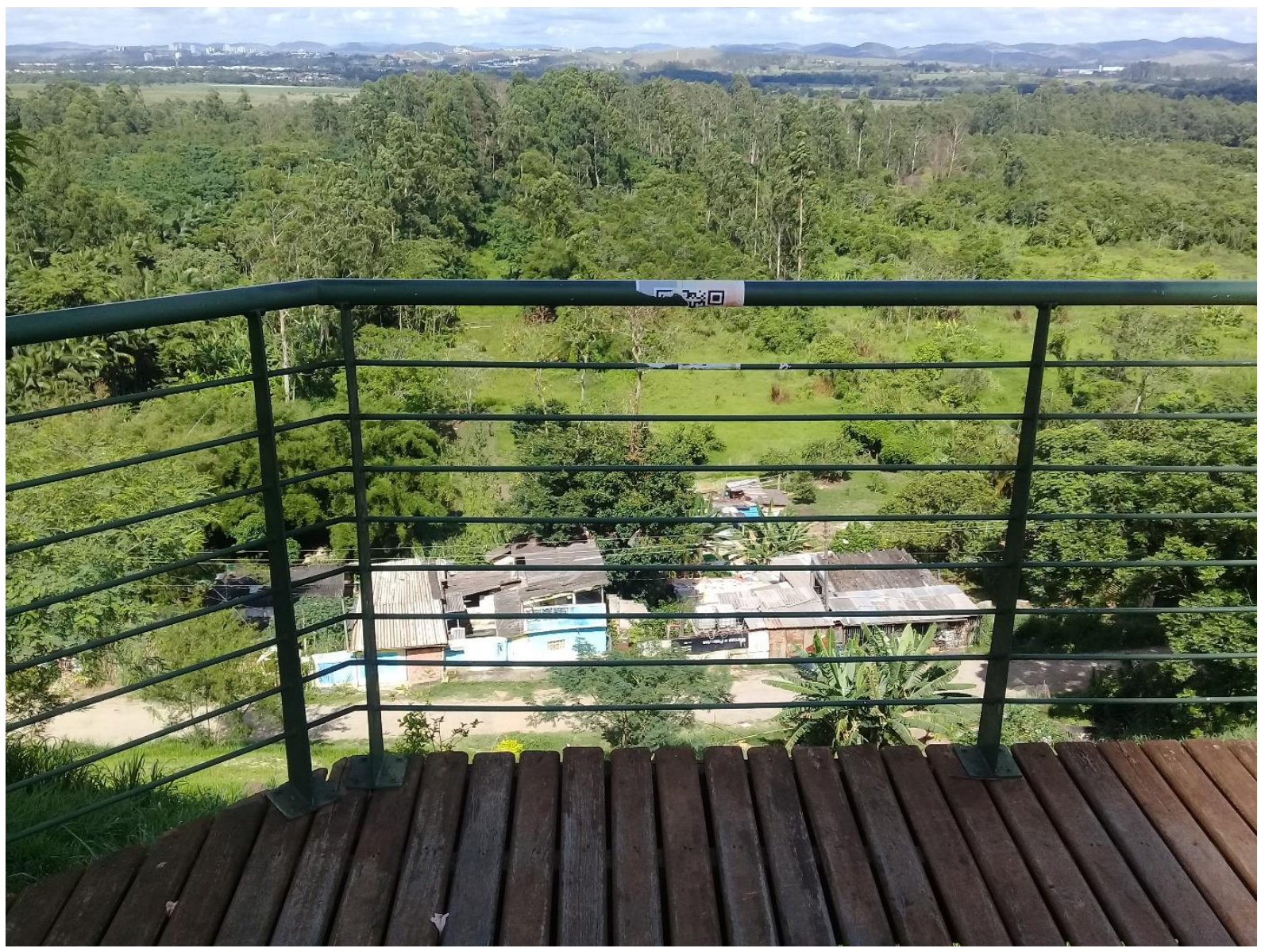

Ver e não olhar (Foto do autor 05) 


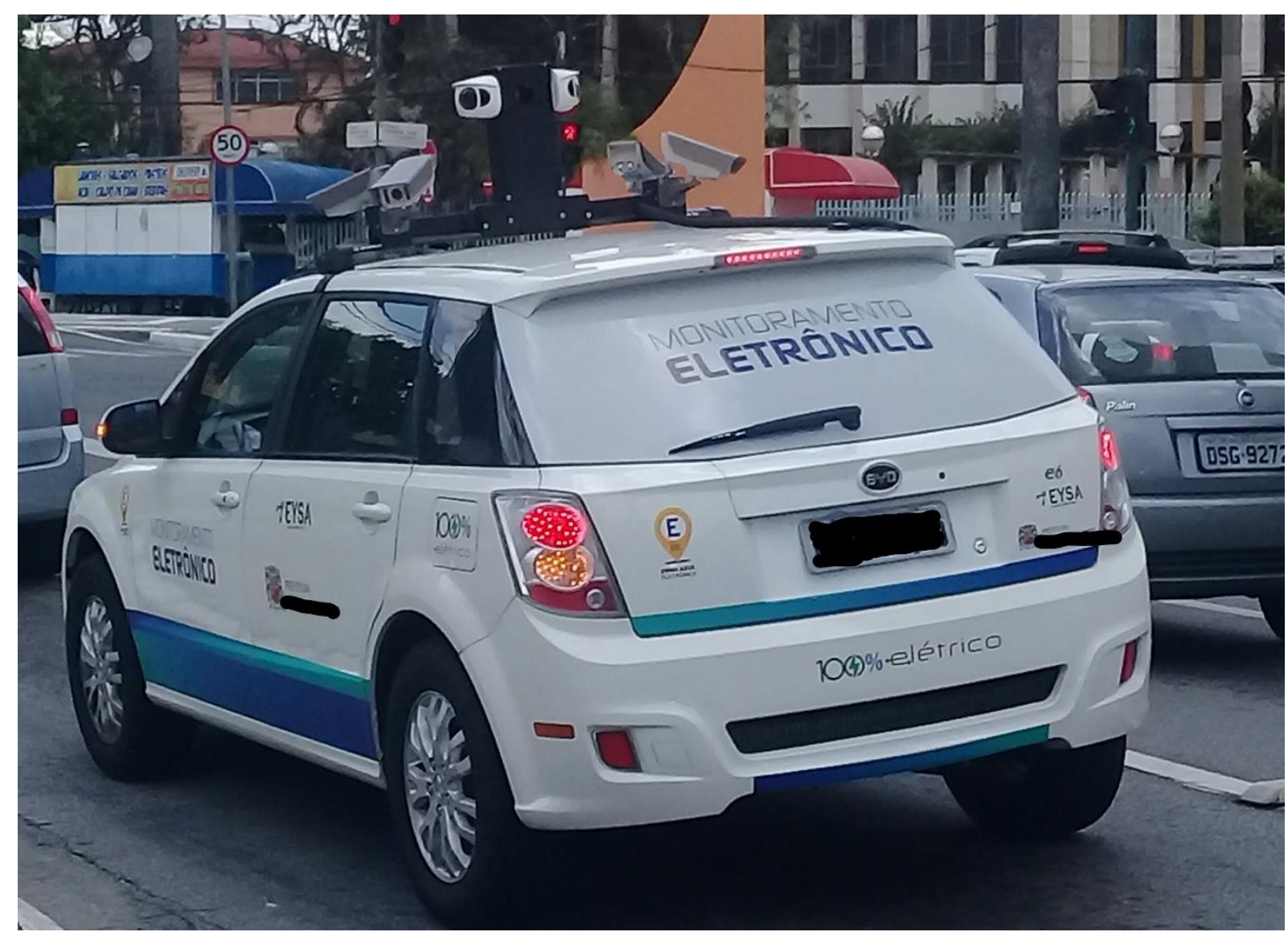

Olhar e não ver (Foto do autor 06)

Compreendemos que o ver esteja relacionado como uma estrutura biológica do sujeito no sentido de constituir uma determinada representação de imagem, enquanto o olhar está relacionado com os aspectos da cultura em que o sujeito pode elaborar o pensamento no entorno da imagem como elemento de determinada representação no conjunto de narrativas que se produzem sobre a realidade.

O "ver, e não olhar" seria a falta de compreensão de que, dentro da cidade, se constroem barreiras difusas que se apresentam em completo antagonismo com os processos para inclusão do outro, uma vez que, ao analisar a realidade, pode se constatar que se constrói espaço como um lugar para não andar ou para impedir a presença do outro. Isso se reflete em um mirante, que expõe ao horizonte uma imagem em que não se coloca em discussão a comunidade que vive segregada da sociedade (Foto do autor 05).

A análise pelo viés da tecnologia se constitui do mesmo processo no campo da razão cínica, pois temos o olhar analítico, que não vê os diversos elementos da contradição que, no caso específico, são as ruas públicas com portarias sobre as quais o poder público não se manifesta a respeito da apropriação do espaço da cidade, com câmeras e sistemas de controle (Foto do autor 06). 
Compreendemos que essas formas de interfaces eletrônicas se constituem num paradigma de imagem da cidade, visto que o sujeito perde a experiência do olhar para a cidade. Portanto, isso se apresenta como um processo formativo que constitui a impossível interpretação crítica sobre os espaços urbanos.

\section{CONCLUSÃO}

Compreendemos que analisar criticamente as representações de imagens da cidade significa levar até às últimas consequências, a pressuposição cartesiana de colocarmos tudo em dúvida. Portanto, devemos estar dispostos a criticar as imagens de representação da cidade no conjunto de narrativas que naturalizam as desigualdades sociais no campo da razão cínica que, em última instância, se apresenta "[...] como categoria adequada para dar conta da dinâmica própria a processos de racionalização social que parecem constituir o fundamento de formas hegemônicas de vida na fase atual do capitalismo" (SAFATLE, 2008, p. 201).

Nesse contexto, o modelo econômico atual se desloca da posição de que "Eles não sabem, mas o fazem" (SAFATLE, 2008, p. 67) para a condição paradoxal de que "[...] eles sabem o que fazem, e continuam a fazê-lo" (SAFATLE, 2008, p. 69). Aqui se encontra o centro da questão deste ensaio, haja visto que as representações de imagens da cidade encontram-se naturalizadas e, portanto, descaracterizam a perda de direito à cidade. A perspectiva da razão crítica deve levar até à última instância a discussão dos motivos que se apresentam nas interdições para os sujeitos deslocarem-se pelos espaços da cidade.

Para se estabelecer a crítica à razão cínica devemos estar dispostos em desacreditarmos as narrativas de sujeitos que se produzem no entorno do nosso modo de ser e ampliarmos a nossa tolerância em relação ao outro. Para tanto, devemos nos arriscar no sentido de conhecer os "labirintos do eu" (COMTE-SPONVILLE, 1997) como forma de ampliarmos a nossa tolerância perante o outro, pois, em última instância, nos desconhecemos como sujeitos, ou seja, somos estranhos a nós mesmos.

Ao conhecermos os "labirintos do eu" podemos descobrir, para o nosso próprio desespero, que "[...] somos personagens sem atores, impostores sem segredos. Somos máscaras sem rosto" (COMTE-SPONVILLE, 1997. p. 56). Em parte, esse não querer saber de si mesmo como estranho é a projeção que se faz no entorno das representações de imagens da cidade, em que, de um lado, ocorre a alienação em não querer saber, e, de outro, o saber que sabe, mas continua fazendo o mesmo nas formas de inconsistência na vida, nas cidades, no modo como se ocupa os espaços urbanos e na exclusão do outro. 
A partir deste ensaio podemos concluir que a perda de direito à cidade se pauta na exclusão sob narrativas em que a questão do outro estranho fica subordinada ao conceito de pertencimento ou a propriedade como parâmetro que possa definir critério de igualdade não democrática.

Não é preciso muito estudo ou pesquisa para tornar evidente que vivemos completamente errados nas diversas interdições que se apresentam nas cidades, como formas de perda de direito a ela, principalmente, e nas diversas formas de exclusão que se impõem de maneira natural e que passam a fazer parte do cotidiano. Na vida em cidade, acabamos por aceitar as diversas formas de poluição com naturalidade, principalmente, ao aceitar isso como resto do sistema produtivo em que pouco se diz a respeito. O pensamento crítico coloca em discussão esses acontecimentos e, portanto, amplia o direito à cidade como modo de se opor às diversas formas de exclusão e ao lucro imediato que se obtém a partir do referido modo de produzir, poluindo o ambiente.

Podemos dizer que vivemos atualmente na cidade que se inclui no paradoxo da exclusão, pois não existe mais o lugar do sujeito, em que tudo se passa nas diversas formas de controle, em que tudo é visto ou gravado. Essa situação coloca em evidência outro modo de representação do espaço urbano no qual as produções ideológicas das mídias eletrônicas naturalizam a realidade e destituem suas contradições em torno de narrativas que se encontram nas questões da política local.

Portanto, partimos para o conceito de ideologia no campo da razão cínica, como forma de pensamento que naturaliza as coisas e destitui as contradições da realidade. Para tanto, a razão cínica se impõe como verdade ao apresentar a realidade na anulação do conjunto de contradições que a compõe. Neste termo, a questão central referente ao pensamento crítico é: como se torna possível a racionalidade se impor no campo da razão cínica e destituir-se como falsa representação da realidade? Em outras palavras, a pergunta filosófica seria: de qual maneira se torna possível reconstituir criticamente a representação da realidade por parte do sujeito? Em que se torna possível compreender como sendo a "síntese de múltiplas determinações" (MARX, 1983. p. 218)?

Para tanto, a destituição e a consequente naturalização da desigualdade na perda do direito à cidade devem se contrapor às representações de imagens que pautam a determinação de única verdade em que se produz as narrativas de como os sujeitos devem circular pelos espaços da cidade.

Compreendemos que o trabalho do pensamento crítico seria a retomada de outro sentido ao desconstruir uma determinada forma de representação de imagem no campo da razão cínica que se impõe como verdade de representação perante a realidade. Essa condição de representação pautada na razão crítica se encontra no campo da política em que o modo de vida dos sujeitos nas cidades pode definir toda uma concepção de mundo, cultura, ciência e, no caso específico deste ensaio, referente à representação da realidade e do contemporâneo das cidades no conjunto das 
contradições em que se apresentam, principalmente, a importância da compreensão referente aos estilos de vida dos sujeitos perante a efetiva ocupação do espaço urbano.

Neste contexto, o referido ensaio se insere no campo da análise crítica da perda do direito à cidade no entorno da razão cínica, que reproduz a verdade a partir das representações de imagens na anulação das contradições da polaridade da representação da realidade entre a cidade aberta e cidade fechada (SENNETT, 2018). Isso se apresenta como elemento natural na vida dos sujeitos nas cidades. Portanto, a questão central pode caminhar para uma resposta no que se refere ao modo como se torna possível desconstruir a naturalização da representação de imagens referentes às barreiras físicas que se encontram presentes nas cidades. Isso se torna o verdadeiro desafio para aqueles que desejam pensar criticamente as cidades.

Compreendemos que a razão cínica se contrapõe aos processos de alienação, no qual não se sabe, mas faz para a condição em que se sabe e continua fazendo no conjunto de atuações nas diversas formas de vidas não democráticas, que fecham as cidades para o outro.

Essas representações de imagens se constituem em distorções performativas na busca por resultados, especialmente na ampliação da audiência de seus seguidores. Compreendemos que, no campo da razão cínica, esses modos de verdade ocorrem nas mediações entre o sujeito e a imagem que eliminam ou destituem os elementos contraditórios da realidade. Neste caso, compreendemos que a representação dos espaços urbanos se encontra, em grande parte, determinada, primordialmente, pelo viés dos dispositivos das mídias eletrônicas que estabelecem a hegemonia da banalização dos elementos da realidade comuns a todos.

Nesta interface entre o sujeito, as imagens no campo das mídias eletrônicas e o espaço urbano é que podemos analisar a representação de imagem da realidade referente ao espaço urbano como perda da experiência do olhar. Portanto, todo esse conjunto de situações que temos na breve exposição desse ensaio, quais sejam, lugar para andar em oposição ao lugar para não andar; rua fechada em oposição à rua aberta e, por último, o olhar que não vê em oposição ao ver que não pode olhar, podem se constituir como heurística para se pensar as imagens de representação da cidade.

Essa forma de realidade, que interdita a passagem do sujeito nos diversos espaços da cidade, se apresenta como forma de senso comum ao determinar os contornos da vida comum para a compreensão do direito privado à cidade.

Espera-se que este ensaio possa se apresentar como incômodo para aqueles que ainda mantêm as imagens de representação da cidade como algo natural à exclusão do outro e, principalmente, pensam essa desapropriação do espaço comum a todos também de modo natural. Portanto, torna-se fundamental para o pensamento crítico que se possam fazer outras narrativas que 
coloquem em discussão as contradições que se apresentam na realidade e espera-se a indignação pelo fato de que existem lugares que, por diversos motivos, encontram-se interditados para o livre deslocamento dos sujeitos nas cidades como forma de resistência à perda de direito à cidade, na direta oposição à razão cínica, como forma de representação de imagem da cidade que naturaliza as referidas perdas do sujeito na ocupação do espaço público.

\section{REFERENCIAS}

ADORNO, Theodor. Educação e Emancipação. Trad. Wolfgang Leo Maar. Rio de Janeiro: Paz e Terra, 1995.

ADORNO, T. \& HORKHEIMER, M. A Dialética do Esclarecimento: fragmentos filosóficos. Rio de Janeiro: Zahar, 1985.

CAPELAS, Bruno. Brasil chega a 168 milhões de smartphones em uso. O Estado de S. Paulo, São Paulo, 14 de abr. 2016. Disponível em: <http://link.estadao.com.br/noticias/gadget,brasil-chega-a168-milhoes-de-smartphones-em-uso,10000047873 >. Acessado em: 10 de mar. 2017.

COMTE-SPONVILLE, André. Os labirintos do eu: o sonho de Narciso. In: desespero e da beatitude. Trad. Eduardo Brandão. São Paulo: Martins Fontes, 1997. . Tratado do

DELEUZE, G. \& GUATTARI, F. 2014. Mil Platôs: capitalismo e esquizofrenia. Trad. Ana Lúcia de Oliveira. Rio de Janeiro: Editora 34.

DESCARTES, René. Discurso do método. Trad. J. Guinsburg e Bento Prado Júnior. $4^{a}$ ed. São Paulo: Nova Cultura, 1987 (Os Pensadores).

DESCARTES, René. Discurso do método. Trad. Maria Emantina Galvão. São Paulo: Martins Fontes, 1996.

FREUD, Sigmund. O Mal-Estar na Civilização (1930 [1929]). In: Obras Completas. v. XXI. Trad. Jayme Salomão. Rio de Janeiro: Imago, 1996.

GHIRALDELLI JR, Paulo. A Filosofia como desbanalização do Brasil. Disponível em: <https://www.portalentretextos.com.br/index.php/post/a-filosofia-como-desbanalizacao-do-brasil > Acessado em 14 jan. 2021.

GORENDER, Jacob. Introdução: o nascimento do materialismo histórico. In: MARX, Karl \& ENGELS, Friedrich. A ideologia alemã. Trad. Luis de Castro e Costa. São Paulo: Martins Fontes, 1998.

HUME, David. Investigação acerca do entendimento humano (1748). Trad. Anoar Aiex. Versão eBook: Edição Acrópolis, 2006

MARX, Karl. Contribuições à crítica da economia política. Trad. Maria Helena Barreiro Alves. $2^{\mathrm{a}}$ ed. São Paulo: Martins Fontes, 1983.

PLATÃO. A República. Trad. Maria Helena da Rocha Pereira. Lisboa: Fundação Gulbenkian, 1996. 
RODRIGUES, Rogério. Apontamentos para construir e habitar cidades abertas: para além de proposição instrumental nas relações dos sujeitos com as cidades. In: Revista e-metropolis. Rio de Janeiro - RJ: Observatório das Metrópoles (UFRJ), No 42, Ano 11, set 2020.

SAFATLE, Vladimir. Cinismo e falência da crítica. São Paulo: Boitempo, 2008.

SENNETT, Richard. Carne e Pedra: o corpo e a cidade na civilização ocidental. Trad. Marcos Arão Reis. Rio de Janeiro: Record, 1997.

SENNETT, Richard. Construir e habitar: ética para uma cidade aberta. Trad. Clóvis Marques. Rio de Janeiro \& São Paulo: Editora Record, 2018.

Trabalho enviado em 06 de fevereiro de $\mathbf{2 0 2 0}$

Aceito em 06 de agosto de 2021 